\title{
Synthesis of $a, \beta$-unsaturated ketones through nickel-catalysed aldehyde-free hydroacylation of alkynes
}

Joon Ho Rhlee

Ulsan National Institute of Science and Technology

\section{Saikat Maiti}

Ulsan National Institute of Science and Technology

Ho Seung Lee

Ulsan National Institute of Science and Technology

Soochan Lee

Ulsan National Institute of Science and Technology

Jaehyun Park

Ulsan National Institute of Science and Technology

Seok Ju Kang

Columbia University https://orcid.org/0000-0002-9921-6674

\section{Yung Sam Kim}

Ulsan National Institute of Science and Technology https://orcid.org/0000-0001-6306-7438

Jeong Kon Seo

Ulsan National Institute of Science and Technology

Kyungjae Myung

Institute for Basic Science (IBS)

\section{Wonyoung Choe}

Ulsan National Insitute of Science and Technology

\section{Sung You Hong ( $\nabla$ syhong@unist.ac.kr)}

Ulsan National Institute of Science and Technology https://orcid.org/0000-0002-5785-4475

\section{Article}

Keywords: Feedstocks, Atom-economical Synthesis, Anti-Markovnikov Selective Coupling, Mechanistic Distinction

Posted Date: January 13th, 2021

DOI: https://doi.org/10.21203/rs.3.rs-108963/v1 
License: (c) (i) This work is licensed under a Creative Commons Attribution 4.0 International License. Read Full License

Version of Record: A version of this preprint was published at Communications Chemistry on February 3rd, 2022. See the published version at https://doi.org/10.1038/s42004-022-00633-3. 


\section{Abstract}

$a, \beta$-Unsaturated ketones are common feedstocks in functional materials, pharmaceuticals and natural compounds. Transition metal-catalysed hydroacylation reactions of alkynes using aldehydes have been widely applied for the atom-economical synthesis of $\alpha, \beta$-unsaturated ketones through chemoselective aldehydic $\mathrm{C}-\mathrm{H}$ activation. However, previous hydroacylation reactions using rhodium, cobalt, or ruthenium catalysts require chelating moiety-bearing aldehydes to prevent undesired decarbonylative product via an unstable acyl-metal-H complex. Herein, we report a nickel-catalysed reductive and antiMarkovnikov selective coupling process to afford non-tethered E-enones from terminal alkynes through an acyl-nickel-thiopyridine complex in the presence of zinc metal as a reducing agent. Utilization of a thioester as an acylating agent and water as a hydrogen donor enables this mechanistically distinctive and aldehyde-free hydroacylation of terminal alkynes under mild reaction conditions at room temperature, with a broad substrate scope including versatile functional groups and even simple aryl and alkyl moieties.

\section{Introduction}

$a, \beta$-Unsaturated ketones have been extensively applied as versatile compounds in synthetic organic chemistry, for example, as key substrates for conjugate addition ${ }^{1-4}$, Morita-Baylis-Hillman ${ }^{5,6}$, DielsAlder $^{7,8}$, and epoxidation ${ }^{9-11}$ reactions. They have been conventionally prepared through aldol condensation $^{12}$, Horner-Wadsworth-Emmons olefination ${ }^{13}$, the dehydrogenation of ketones ${ }^{14,15}$, or palladium-catalysed carbonylation ${ }^{16,17}$ reactions. However, these methods often require prefunctionalized substrates or operate through multi-step sequences. Alkynes have widely applied as readily available synthetic platforms for catalytic transformations to directly access functionalized cyclic or acyclic products ${ }^{18-22}$. The catalytic hydroacylation of alkynes using aldehydes inherently provides an atom-economical process leading to the formation of enones. Organocatalytic intramolecular hydroacylation reactions of alkynes using organophosphines or $N$-heterocyclic carbenes have been demonstrated (Fig. 1a) ${ }^{23-25}$. Metal-catalysed intermolecular hydroacylation has emerged as a prominent method for rapidly accessing $E$-enones through alkyne-aldehyde coupling ${ }^{26-31}$. This atom-economical method involves the chemoselective activation of an aldehydic $\mathrm{C}\left(s p^{2}\right)-\mathrm{H}$, and chelating moiety-bearing aldehydes have been applied to prevent decarbonylative side pathways (Fig. 1b).

Stabilization of an acyl-metal complex assisted by heteroatom chelation is a powerful strategy for obtaining E-enones. However, the installation and removal of the coordinating moieties entailed extra synthetic steps while reducing the step economy of the hydrofunctionalization. Though nondirected hydroacylation methods have been developed for alkenes or dienes ${ }^{32-36}$, to our knowledge, there is no general hydroacylation method for unactivated terminal alkynes that lead to chelating moiety-free $E$ enones. Recently, the Weix group reported that 2-thiopyridyl esters act as potential acyl donors for crosselectrophile coupling reactions ${ }^{37}$. We surmised that a thioester may act as both a transient thiopyridyl (SPy) ligand and an acyl component under nickel-catalysed reductive coupling conditions to lead to acyl- 
Ni-SPy complex. A consecutive alkyne insertion and subsequent protodemetalation process may lead to hydroacylation product formation (Fig. 1c). However, the challenges of this anticipated reaction process to attain traceless alkyne hydroacylation are fourfold: (i) competition with non-conjunctive crosselectrophile (proton and thioester) coupling, (ii) reduction of substrates, (iii) iterative alkyne additions, and (vi) regio- and stereoselectivity issues. Therefore, precise reactivity and selectivity control is crucial for a general approach to the hydroacylation of unactivated terminal alkynes.

\section{Results}

Optimisation studies. To optimize the reaction conditions, $S$ (pyridin-2-yl) 4-methoxybenzothioate (1) and 3,3-dimethyl-1-butyne (2) were chosen as model substrates, and a thorough screening of catalysts, reducing agents, additives, and solvents was conducted (Table 1, see also the Supplementary Information, Section III). The standard conditions were established on the basis of inexpensive nickel(II) perchlorate hexahydrate, $\mathrm{Zn}$, and $\mathrm{ZnCl}_{2}$ in 1,2-DME to exclusively afford $E$-enone $\mathbf{3}$ in $81 \%$ isolated yield at room temperature (entry 1 ). The use of THF resulted in a similar yield (entry 2 ). Interestingly, coordinated water molecules were also found to be a suitable proton source (entries $3-5$ ). The use of $17 \mathrm{~mol} \%$ of $\mathrm{Ni}$ catalyst was appropriate for providing a stoichiometric 1 equiv of protons to the reaction. No desired product formation was observed in the absence of the nickel catalyst, $\mathrm{Zn}$, or $\mathrm{ZnCl}_{2}$ (entries 6-8). Mn as the reducing agent instead of $\mathrm{Zn}$ also appeared successful; however, this resulted in a diminished yield (entry 9). $\mathrm{ZnCl}_{2}$ was found to be superior to $\mathrm{MgCl}_{2}$ (entry 10). Using 1.5 equiv of terminal alkyne 2 was required for better conversion of the thioester (entry 11). The standard optimized reaction conditions were developed under an inert argon atmosphere; however, a significant amount of product formation was observed even under open atmosphere conditions (entry 12). Reduced reaction time or a decreased amount of Ni catalyst led to diminished yields (entries 13,14 ). In addition, the employment of acyl chloride or aldehyde as an acyl donor instead of thioester appeared to be completely unproductive (entries 15, 16). Additional ligands in the hydroacylation resulted in slightly diminished yields (entries 17 , 18).

Scope of the reaction. With the optimized conditions in hand, we set out to explore the generality of this alkyne hydroacylation by determining the thioester scope (Table 2). Various alkyl substituents worked well to afford E-enone products (5-8) in moderate to good yields. Hydrogen and phenyl groups, however, led to slightly lower yields $(4,9)$. Generally, electron donating groups gave the products in moderate to good yields (10-13). Although yields were low, halide groups were tolerated in the reaction (14-16). Electron withdrawing groups such as $\mathrm{CO}_{2} \mathrm{Me}$ and $\mathrm{CF}_{3}$ led to products $(17,18)$ with low yields. Meta- and ortho-substitution patterns also provided the products in moderate yields (19-24). A 2-naphthyl substituent afforded the product in a slightly higher yield (44\%) than a 1-naphthyl substituent (32\%) (25, 26). An electron-rich indole substituent led to product 27 with $82 \%$ yield. Both acyclic- and cyclic aliphatic substituents could access the products with moderate yields (28-32). 
We then examined the scope of a wide range of alkynes. Acyclic- as well as cyclic aliphatic terminal alkynes underwent the reaction to afford the corresponding vinyl ketones (33-38) in moderate yields, although cyclopropyl- and cyclopentyl-derived alkynes gave the diminished yields. Aromatic alkynes bearing alkyl, phenyl, and phenoxy substituents worked well to give the desired products (39-45) with moderate to good yields. Ortho-, meta-, and para-substituted methoxy groups were also tolerated to obtain the products (46-48). Product 49 was isolated in $55 \%$ yield by using a disubstituted arylalkyne. Fluoro- and chloro- groups were examined and gave $\mathbf{5 0}$ and $\mathbf{5 1}$ in $69 \%$ and $56 \%$ yields, respectively. The strongly electron withdrawing trifluoromethyl group led to product formation $(52,53)$ with diminished yields. 2-Ethylnyl-6-methoxy-naphthalene efficiently produced $\mathbf{5 4}$ in 76\% yield. 2-Ethynylthiophene and 3ethynylthiophene underwent the reaction smoothly to obtain the corresponding products $(\mathbf{5 5}, \mathbf{5 6})$ in $39 \%$ and $58 \%$ yields, respectively. A free hydroxyl group was compatible affording 57 in $62 \%$ yield. We were delighted to find that the reaction was feasible with ethisterone, an agent for gynecological disease treatment, to afford $\mathbf{5 8}$ in $56 \%$ yield. The chemistry was also operative on a $1 \mathrm{mmol}$ scale to give a similar yield. Interestingly, symmetrical as well as unsymmetrical internal alkynes gave hydroacylation products (59-61), albeit in low yields. Activated alkenes also underwent the reaction very smoothly to afford $62-$ 64 in good yields.

Mechanistic investigations and deuterium labeling experiments. Control experiments were conducted to gain the insight into the reaction pathway. When TEMPO was added under the standard reaction conditions, the desired hydroacylation completely shut down and an acyl-TEMPO adduct (65) was isolated in $70 \%$ yield. This study corroborates the involvement of an acyl radical intermediate during the course of the reaction (Fig. 2a). Remarkably, formation of the acyl-TEMPO adduct was also observed by employing $\mathrm{Zn}$ and $\mathrm{ZnCl}_{2}$ in the absence of any nickel catalyst, indicating its role in acyl radical generation from the thioester through single-electron transfer (SET). The formation of hydroacylation product 60 suggests the protodemetalation of nucleophilic vinyl nickel complex $\mathbf{I}^{38}$. Interestingly, formation of $\mathbf{6 6}$ was also observed verifying an iterative double alkyne insertion (Fig. 2b). In addition to this, cyclic product $\mathbf{6 7}$ was isolated illustrating the intermediacy of vinyl nickel species $\|^{39,40}$. To identify the proton source of the hydroacylation, deuterium labeling tests were performed (Fig. 2c). First, a reaction conducted using deuterium oxide (3.0 equiv) resulted in formation of the product with $64 \%$ and $33 \%$ [D] incorporation at the b- and a-positions, respectively, of unsaturated ketone [D]-3. Employing deuterated nickel(II) perchlorate hexahydrate resulted in the similar ratio of 1.9:1 (i.e. 38\%:20\%, see also the Supplementary Information, Section V). To confirm the non-involvement of solvent molecules, we performed the hydroacylation reaction using deuterated THF, and no D-incorporation was detected in the final product. The employment of terminally deuterated alkyne [D]-2 for the Ni-catalysed reductive coupling reaction also demonstrated $\mathrm{H}-\mathrm{D}$ exchange resulting from the weak acidity of the terminal alkyne $\mathrm{e}^{41,42}$. 
Proposed mechanism. Based on the above mechanistic studies and findings from previous reports ${ }^{38-}$ $40,43,44$, we proposed a reaction pathway for this reductive hydroacylation as illustrated in Fig. 3 . The reaction is initiated by the generation of an acyl radical and a thiopyridyl anion through the singleelectron reduction of a redox-active thioester promoted by $\mathrm{Zn}$ and $\mathrm{ZnCl}_{2}$. The SPy anion can undergo a consecutive ligand exchange reaction with the nickel $(\mathrm{I}) \mathrm{X} \mathrm{A}$, which is generated in-situ from the reduction of the $\mathrm{Ni}(\mathrm{II}) \mathrm{X}_{2}$ pre-catalyst by $\mathrm{Zn} / \mathrm{ZnCl}_{2}$. Engagement of the acyl radical with intermediate $\mathrm{A}$ directs the formation of acyl-Ni(II)-X complex B. Migratory insertion of terminal alkynes gives rise to vinyl nickel complex $\mathbf{D}$. Then, protodemetalation of nucleophilic vinyl Ni(II) species $\mathbf{D}$ with the help of water affords the desired $E$-enone ${ }^{38}$. The reduction of $\mathrm{Ni}(\mathrm{II})(\mathrm{OH}) \mathrm{X}$ species $\mathrm{E}$ by zinc regenerates the active $\mathrm{Ni}(\mathrm{I})$ species A.

\section{Conclusions}

In summary, we have demonstrated a nickel-catalysed hydroacylation approach using terminal alkynes to exclusively afford non-tethered E-enones. This nondirected and aldehyde-free process proceeds by the single-electron reduction of a redox-active 2-pyridyl thioester to give an acyl radical that is promoted by $\mathrm{Zn} / \mathrm{ZnCl}_{2}$. It requires neither additional steps for removal of the coordinating group, nor use of a nucleophilic hydride source, further enhancing the efficacy of the method. We anticipate that these $\mathrm{Ni}$ catalysed reductive hydroacylation reactions will have an impact on synthesizing important synthetic intermediates, functional materials and pharmaceuticals.

\section{Methods}

General experimental procedure for E-enones. A 1-dram screw-cap vial equipped with a magnetic stir bar was charged with thioester ( $0.2 \mathrm{mmol}, 1.0$ equiv), $\mathrm{Zn}$ (33 mg, $0.5 \mathrm{mmol}, 2.5$ equiv), $\mathrm{ZnCl}_{2}$ (27 mg, 0.2 mmol, 1.0 equiv), and $\mathrm{Ni}\left(\mathrm{ClO}_{4}\right)_{2} \cdot 6 \mathrm{H}_{2} \mathrm{O}(12 \mathrm{mg}, 0.034 \mathrm{mmol}, 17 \mathrm{~mol} \%)$ inside a glove box. The mixture was dissolved in 1,2-DME ( $1 \mathrm{~mL})$. Then, alkyne ( $0.3 \mathrm{mmol}, 1.5$ equiv) was added. The reaction mixture was stirred for $24 \mathrm{~h}$ at room temperature. After completion of the reaction, the mixture was purified by flash column chromatography to afford the desired product.

\section{Data availability}

Detailed experimental procedures, HRMS-ESI data and NMR spectra (PDF) for all compounds were provided in the Supplementary Information. Single crystal X-ray data for $\mathbf{2 7}$ and $\mathbf{6 7}$ (CIF) are available free of charge from the Cambridge Crystallographic Database Centre (CCDC) under reference numbers 2039192 and 2036543.

\section{References}


1. Wu, H., Garcia, J. M., Haeffner, F., Radomkit, S., Zhugralin, A. R. \& Hoveyda, A. H. Mechanism of NHCcatalyzed conjugate additions of diboron and borosilane reagents to a, $\beta$-unsaturated carbonyl compounds. J. Am. Chem. Soc. 137, 10585-10602 (2015).

2. Wu, F., Li, H., Hong, R. \& Deng, L. Construction of quaternary stereocenters by efficient and practical conjugate additions to a, $\beta$-unsaturated ketones with a chiral organic catalyst. Angew. Chem. Int. Ed. 45, 947-950 (2006).

3. Lee, S., Lim, C. J., Kim, S., Subramaniam, R., Zimmerman, J. \& Sibi, M. P. Enantioselective conjugate radical addition to a'-hydroxy enones. Org. Lett.8, 4311-4313 (2006).

4. Chi, Y. \& Gellman, S. H. Diphenylprolinol methyl ether: a highly enantioselective catalyst for Michael addition of aldehydes to simple enones. Org. Lett. 7, 4253-4256 (2005).

5. Li, Y.-Q., Wang, H.-J. \& Huang, Z.-Z. Morita-Baylis-Hillman reaction of a, $\beta$-unsaturated ketones with allylic acetates by the combination of transition-metal catalysis and organomediation. J. Org. Chem. 81, 4429-4433 (2016).

6. Satpathi, B. \& Ramasastry, S. S. V. Morita-Baylis-Hillman reaction of $\beta, \beta$-disubstituted enones: an enantioselective organocatalytic approach for the synthesis of cyclopenta[b]annulated arenes and heteroarenes. Angew. Chem. Int. Ed. 55, 1777-1781 (2016).

7. Singh, R. P., Bartelson, K., Wang, Y., Su, H., Lu, X. \& Deng, L. Enantioselective Diels-Alder Reaction of simple a, $\beta$-unsaturated ketones with a cinchona alkaloid catalyst. J. Am. Chem. Soc. 130, 24222423 (2008).

8. Northrup, A. B. \& MacMillan, D. W. C. The first general enantioselective catalytic Diels-Alder reaction with simple a,ß-unsaturated ketones. J. Am. Chem. Soc. 124, 2458-2460 (2002).

9. Lifchits, O., Mahlau, M., Reisinger, C. M., Lee, A., Fares, C., Polyak, I., Gopakumar, G., Thiel, W. \& List, B. The cinchona primary amine-catalyzed asymmetric epoxidation and hydroperoxidation of a, $\beta$ unsaturated carbonyl compounds with hydrogen peroxide. J. Am. Chem. Soc. 135, 6677-6693 (2013).

10. Chu, Y., Liu, X., Li, W., Hu, X., Lin, L. \& Feng, X. Asymmetric catalytic epoxidation of a, $\beta$-unsaturated carbonyl compounds with hydrogen peroxide: additive-free and wide substrate scope. Chem. Sci. $\mathbf{3}$, 1996-2000 (2012).

11. Ooi, T., Ohara, D., Tamura, M. \& Maruoka, K. Design of new chiral phase-transfer catalysts with dual functions for highly enantioselective epoxidation of a,ß-unsaturated ketones. J. Am. Chem. Soc. 126, 6844-6845 (2004).

12. Wang, W., Mei, Y., Li, H. \& Wang, J. A novel pyrrolidine imide catalyzed direct formation of a, $\beta$ unsaturated ketones from unmodified ketones and aldehydes. Org. Lett. 7, 601-604 (2005).

13. Umezawa, T., Seino, T. \& Matsuda, F. Novel one-pot three-component coupling reaction with trimethylsilylmethyl-phosphonate, acyl fluoride, and aldehyde through the Horner-WadsworthEmmons reaction. Org. Lett. 14, 4206-4209 (2012).

14. Hirao, T. Synthetic strategy: palladium-catalyzed dehydrogenation of carbonyl compounds. J. Org. Chem. 84, 1687-1692 (2019). 
15. Diao, T. \& Stahl, S. S. Synthesis of cyclic enones via direct palladium-catalyzed aerobic dehydrogenation of ketones. J. Am. Chem. Soc. 133, 14566-14569 (2011).

16. Zhang, S., Neumann, H. \& Beller, M. Synthesis of a,ß-unsaturated carbonyl compounds by carbonylation reactions. Chem. Soc. Rev. 49, 3187-3210 (2020).

17. Zhang, S., Neumann, H. \& Beller, M. Pd-catalyzed synthesis of a,ß-unsaturated ketones by carbonylation of vinyl triflates and nonaflates. Chem. Commun. 55, 5938-5941 (2019).

18. Gao, D.-W. et al. Cascade CuH-catalysed conversion of alkynes into enantioenriched 1,1-disubstituted products. Nat. Catal. 3, 23-29 (2020).

19. Derosa, J., Tran, V. T., Boulous, M. N., Chen, J. S. \& Engle, K. M. Nickel-catalyzed $\beta, Y^{-}$ dicarbofunctionalization of alkenyl carbonyl compounds via conjunctive cross-coupling. J. Am. Chem. Soc. 139, 10657-10660 (2017).

20. Kim, W. G. et al. Nickel-Catalyzed azide-alkyne cycloaddition to access 1,5-disubstituted 1,2,3triazoles in air and water. J. Am. Chem. Soc. 139, 12121-12124 (2017).

21. Zhang, L., Lovinger, G. J., Edelstein, E. K., Szymaniak, A. A., Chierchia, M. P. \& Morken, J. P. Catalytic conjunctive cross-coupling enabled by metal-induced metallate rearrangement. Science $351,70-74$ (2016).

22. Li, L. \& Herzon, S. B. Temporal separation of catalytic activities allows anti-Markovnikov reductive functionalization of terminal alkynes. Nat. Chem. 6, 22-27 (2014).

23. Mondal, A., Hazra, R., Grover, J., Raghu, M. \& Ramasastry, S. S. V. Organophosphine-catalyzed intramolecular hydroacylation of activated alkynes. ACS Catal. 8, 2748-2753 (2018).

24. Vedachalam, S., Wong, Q.-L., Maji, B., Zeng, J., Ma, J. \& Liu, X.-W. N-Heterocyclic carbene catalyzed intramolecular hydroacylation of activated alkynes: synthesis of chromones. Adv. Synth. Catal. 353, 219-225 (2011).

25. Biju, A. T., Wurz, N. E. \& Glorius, F. N-Heterocyclic carbene-catalyzed cascade reaction involving the hydroacylation of unactivated alkynes. J. Am. Chem. Soc. 132, 5970-5971 (2010).

26. Coxon, T. J., Fernandez, M., Barwick-Silk, J., McKay, A. I., Britton, L. E., Weller, A. S. \& Willis, M. C. Exploiting carbonyl groups to control intermolecular rhodium-catalyzed alkene and alkyne hydroacylation. J. Am. Chem. Soc. 139, 10142-10149 (2017).

27. Ghosh, A., Johnson, K. F., Vickerman, K. L., Walker, J. A. \& Standley, L. M. Recent advances in transition metal-catalysed hydroacylation of alkenes and alkynes. Org. Chem. Front. 3, 639-644 (2016).

28. Neuhaus, J. D., Morrow, S. M., Brunavs, M. \& Willis, M. C. Diversely substituted quinolines via rhodium-catalyzed alkyne hydroacylation, Org. Lett. 18, 1562-1565 (2016).

29. Castaing, M., Wason, S. L., Estepa, B.; Hooper, J. F. \& Willis, M. C. 2-Aminobenzaldehydes as versatile substrates for rhodium-catalyzed alkyne hydroacylation: application to dihydroquinolone synthesis. Angew. Chem. Int. Ed. 52, 13280-13283 (2013). 
30. Willis, M. C. Transition metal catalyzed alkene and alkyne hydroacylation. Chem. Rev. 110, 725-748 (2010).

31. Jun, C.-H., Lee, H., Hong, J.-B. \& Kwon, B.-I. Efficient and selective hydroacylation of 1-alkynes with aldehydes by a chelation-assisted catalytic system. Angew. Chem. Int. Ed. 41, 2146-2147 (2002).

32. Zhou, Y., Bandar, J. S. \& Buchwald, S. L. Enantioselective CuH-catalyzed hydroacylation employing unsaturated carboxylic acids as aldehyde surrogates. J. Am. Chem. Soc. 139, 8126-8129 (2017).

33. Ociepa, M., Baka, O., Narodowiec, J. \& Gryko, D. Light-driven vitamin $\mathrm{B}_{12}$-catalyzed generation of acyl radicals from 2-S-pyridyl thioesters. Adv. Synth. Catal. 359, 3560-3565 (2017).

34. Chen, Q.-A., Kim, D. K. \& Dong, V. M. Regioselective hydroacylation of 1,3-dienes by cobalt catalysis. J. Am. Chem. Soc.136, 3772-3775 (2014).

35. Leung, J. C. \& Krische, M. J. Catalytic intermolecular hydroacylation of C-C $\pi$-bonds in the absence of chelation assistance. Chem. Sci. 3, 2202-2209 (2012).

36. Omura, S., Fukuyama, T., Horiguchi, J., Murakami, Y. \& Ryu, I. Ruthenium hydride-catalyzed addition of aldehydes to dienes leading to $\beta, Y$-unsaturated ketones. J. Am. Chem. Soc.130, 14094-14095 (2008).

37. Wang, J., Cary, B. P., Beyer, P. D., Gellman, S. H. \& Weix, D. J. Ketones from nickel-catalyzed decarboxylative, non-symmetric cross-electrophile coupling of carboxylic acid esters. Angew. Chem. Int. Ed., 58, 12081-12085 (2019).

38. Iqbal, N., Iqbal, N., Maiti, D. \& Cho, E. J. Access to multifunctionalized benzofurans by aryl nickelation of alkynes: efficient synthesis of the anti-arrhythmic drug amiodarone. Angew. Chem. Int. Ed. 58, 15808-15812 (2019).

39. Barber, E. R., Hynds, H. M., Stephens, C. P., Lemons, H. E., Fredrickson, E. T. \& Wilger, D. J. Nickelcatalyzed Hydroarylation of alkynes under reductive conditions with aryl bromides and water. J. Org. Chem. 84, 11612-11622 (2019).

40. Zhang, X., Xie, X. \& Liu, Y. Nickel-catalyzed highly regioselective hydrocyanation of terminal alkynes with $\mathrm{Zn}(\mathrm{CN})_{2}$ using water as the hydrogen source. J. Am. Chem. Soc. 140, 7385-7389 (2018).

41. Chatterjee, B. \& Gunanathan, C. The ruthenium-catalysed selective synthesis of mono-deuterated terminal alkynes. Chem. Commun. 52, 4509-4512 (2016).

42. Arndt, M., Salih, K. S. M., Fromm, A., Goossen, L. J., Menges, F. \& Niedner-Schatteburg, G. Mechanistic investigation of the Ru-catalyzed hydroamidation of terminal alkynes. J. Am. Chem. Soc. 133, 74287449 (2011).

43. Richmond, E. \& Moran, S. Recent advances in nickel catalysis enabled by stoichiometric metallic reducing agents. Synthesis 50, 499-513 (2018).

44. Huihui, K. M. M. et al. Decarboxylative cross-electrophile coupling of $N$-hydroxyphthalimide esters with aryl iodides. J. Am. Chem. Soc. 138, 5016-5019 (2016).

\section{Declarations}




\section{Acknowledgements}

The authors are grateful for financial support provided by Electronics and Telecommunications Research Institute (ETRI) grant funded by the Korea government (20ZB1200, development of ICT materials, components and equipment technologies). W.C. acknowledges Pohang Accelerator Laboratory for 2D beamline use (2020-3rd-2D-012). S.M. is grateful for the financial support from the Institute of Basic Science (IBS-R022-D1) Korea.

\section{Author contributions}

J.H.R., S.M., K.M., and S.Y.H. conceived the project. J.H.R., S.M., and H.S.L. prepared substrates, and examined the catalytic reactions. S.L. and W.C. solved single crystal X-ray structures of compounds 27 and 67. J.H.R., J.P., S.J.K., Y.S.K., and J.K.S. worked on analytical sections for the mechanistic and deuterium labeling experiments. J.H.R., S.M., and S.Y.H. wrote the manuscript. All authors discussed results and provided input on the manuscript.

\section{Competing interests}

The authors declare no competing interests.

\section{Tables}

Tables 1 and 2 are available in the Supplementary Files.

\section{Figures}


a Intramolecular organocatalytic approach<smiles>[R]C#CCOc1ccccc1C=O</smiles>

b $\mathrm{C}-\mathrm{H}$ activation approach

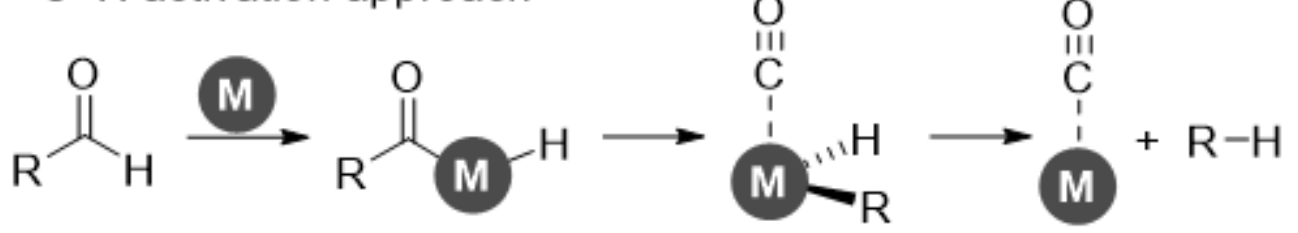
unstable complex<smiles>[R]C=CC(=O)CC([R])[X]</smiles>
M = mainly $\mathrm{Rh}$ chelation-stabilized chelating-moiety $(X)-$ bearing $E$-enones $X$ = chelating moiety

C This Work: nondirected and aldehyde-free approach

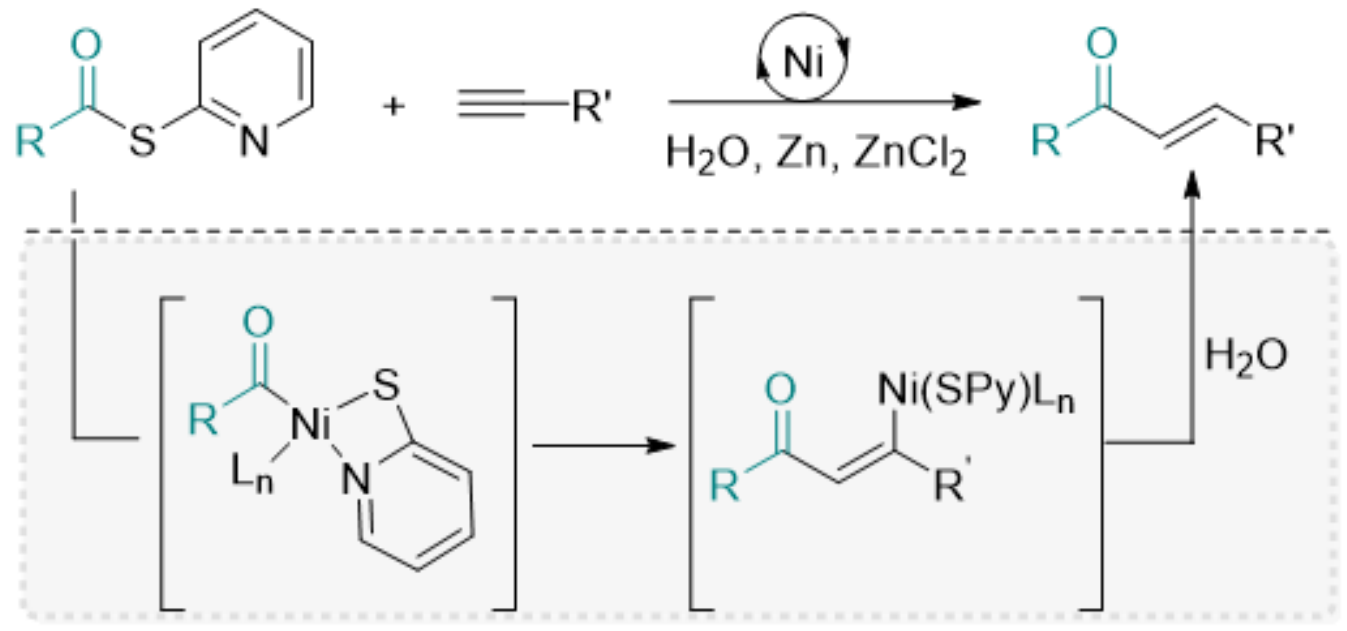

\section{Figure 1}

Hydroacylation of alkynes. Previous works: aldehyde-alkyne coupling. a, Intramolecular organocatalytic approach. b, C-H activation approach. c, this work: non-directed and aldehyde-free approach. 
a Trapping of acyl radical

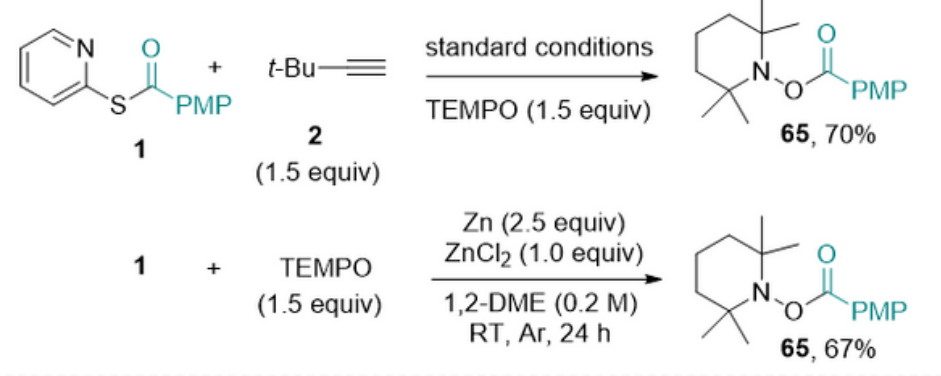

b Iterative alkyne insertion

1

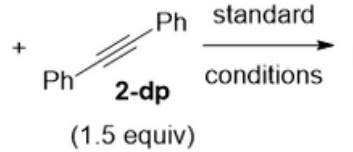<smiles>CC(=C(C(N)=O)c1ccccc1)c1ccccc1</smiles>
I

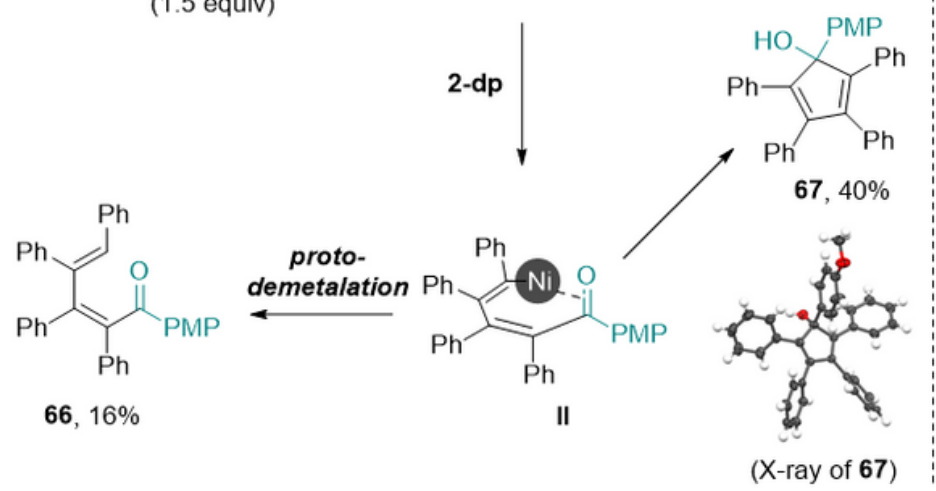

c Deuterium labeling

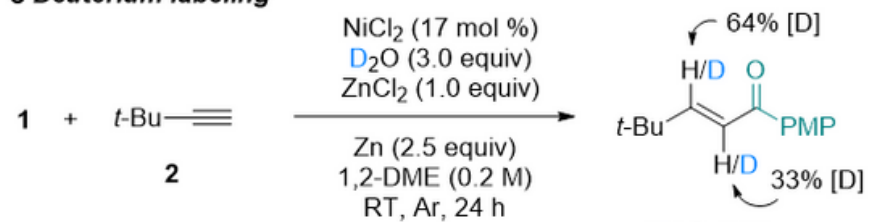

[D]-3, 54\%
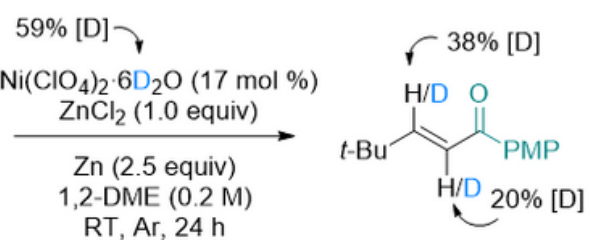

[D]-3, 70\%

$1+t-\mathrm{Bu} \longrightarrow \frac{\substack{\mathrm{Ni}\left(\mathrm{ClO}_{4}\right)_{2} \cdot 6 \mathrm{H}_{2} \mathrm{O}(17 \mathrm{~mol} \%) \\ \mathrm{ZnCl}(1.0 \text { equiv })}}{\substack{\mathrm{Zn}(2.5 \text { equiv }) \\ \mathrm{THF}-d_{8}(0.2 \mathrm{M}) \\ \mathrm{RT}, \mathrm{Ar}, 24 \mathrm{~h}}}$

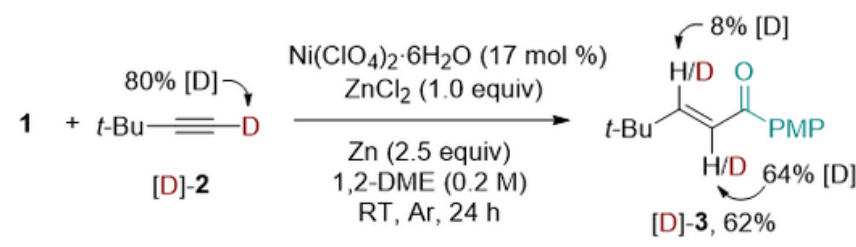

\section{Figure 2}

Mechanistic and deuterium labeling studies. a, Trapping of acyl radical. b, Iterative alkyne insertion. c, Deuterium labeling. 


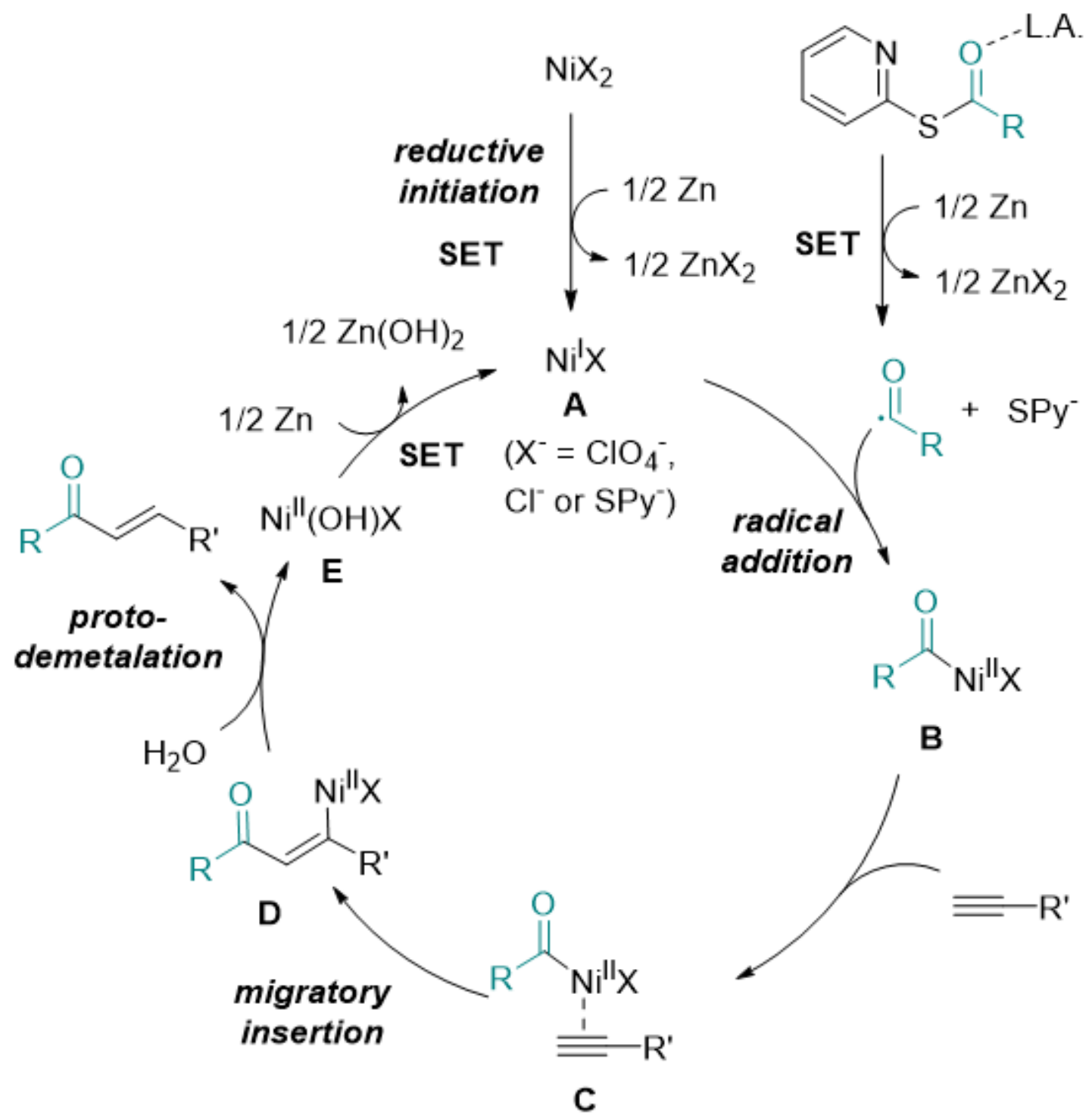

Figure 3

Proposed mechanism of Ni-catalysed aldehyde-free alkyne hydroacylation

\section{Supplementary Files}

This is a list of supplementary files associated with this preprint. Click to download.

- CommunChemSIfinal.docx

- Tables.docx

- compound67checkcif.pdf

- compound27checkcif.pdf 